\title{
Prevalence and Levels of Depression Among Parents of Children with Cancer in Basrah, Iraq
}

$$
\begin{gathered}
\text { معدل انتشار ومستويات الاكتئاب بين آباء وأمهات الأطفال المصابين بالسرطان } \\
\text { في البصرة، العراق }
\end{gathered}
$$$$
\text { شكرية كامل المالكي، جاسم الأسدي، عقيل الوائلي، صباح أغا }
$$

ABSTRACT: Objectives: Cancer in a family member can be a major source of psychological disorders, especially for the parents of children diagnosed with cancer. This study aimed to determine the prevalence and levels of depression among parents of children with cancer in Basrah, Iraq. Methods: This cross-sectional study was conducted between November 2014 and April 2015 at the Specialist Paediatric Hospital in Basrah City, Iraq. One parent each of 384 children with cancer admitted to the hospital for treatment or follow-up during the study period were invited to participate in the study. Age, gender, years of education, occupation, monthly income, place of residence and the overall number of children in a family were recorded. The Center for Epidemiologic Studies Depression Scale was used to identify depression and assess levels of depression. Results: A total of 336 parents participated in the study (response rate: $87.5 \%$ ). Of these, $70.5 \%$ were depressed, $54.1 \%$ of which had major depression. Depression was significantly more common ( $77.2 \%$ versus $57.1 \%)$ and more severe (60.7\% versus $41.1 \%)$ among mothers compared to fathers $(P=0.001)$. Parents with fewer years of education were more likely to be depressed; this association was significant for mothers but not fathers $(P=0.001$ and 0.814 , respectively). Depression was significantly inversely associated with monthly income $(P=0.001)$. Conclusion: The prevalence of depression among the parents of children with cancer was high. Depression was significantly more severe among mothers compared to fathers and among mothers who were less educated. Income also had a significant association with levels of depression among parents.

Keywords: Cancer; Children; Parents; Depression; Prevalence; Iraq.

الملخص: أهداف: السرطان في أحد أفراد الأسرة يمكن أن يكون مصدراً رئيسياً للصدمة النفسية، خاصة بالنساء النسبة لآباء وأمهات الأطفال

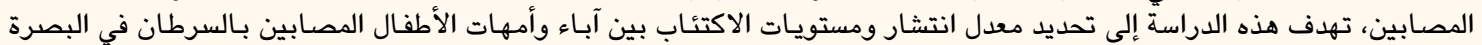

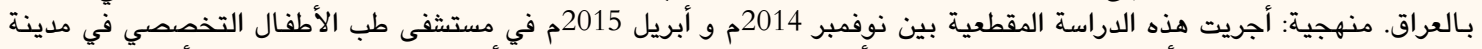

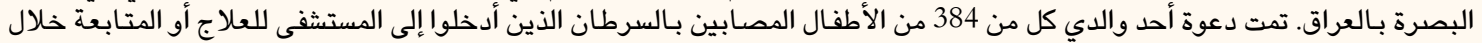

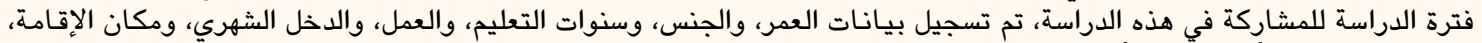

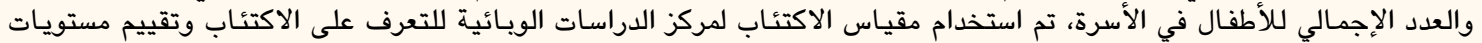

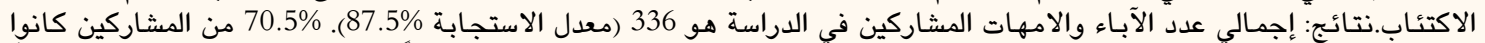

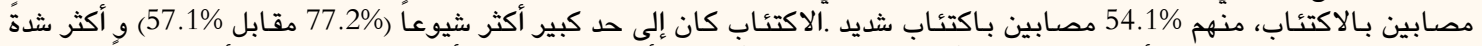

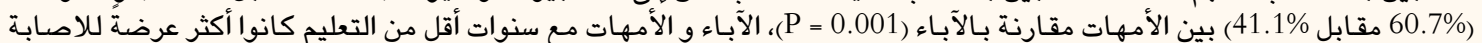

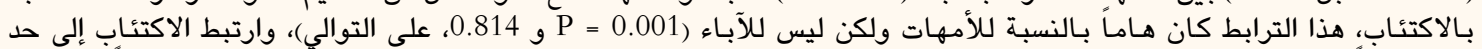

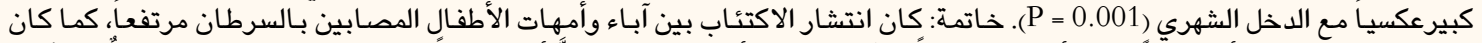

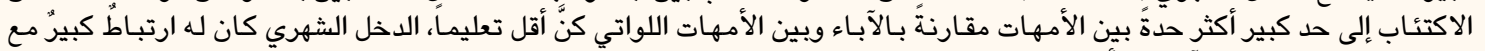

$$
\text { مستويات الاكتئاب بين الآباء والأمهات الأبن الأبنات }
$$

$$
\text { كلمات مفتاحية: السرطان؛ الأطفال؛ الآباء والأمهات؛ الاكتئاب؛ انتشار؛ العراق. }
$$

\section{ADVANCES IN KNOWLEDGE}

Psychological disorders among the parents or family members of a child with cancer constitute an important health problem. The results of this study showed that the prevalence of depression among parents of children with cancer in Basrah, Iraq, was very high.

To the best of the authors' knowledge, this is the first study from Basrah, Iraq, to explore this health problem.

\section{Application to Patient Care}

It is critical to consider the mental health of parents of children with cancer, not only for the sake of the parents but also because depressed parents may often not be able to adequately care for their children. The results of this study may encourage the implementation of preventative interventions to reduce levels of depression among the parents of children with cancer in this region. 
A DIAGNOSIS OF CANCER IN A FAMILY member, especially a child, is often a source of stress to the entire family and can have a psychological effect on the patient's parents; in contrast, children diagnosed with cancer tend to be affected physically rather than psychologically. ${ }^{1}$ Research conducted on this subject has indicated that parents of cancer patients go through predictable and permanent lifestyle changes after their children are diagnosed with cancer. ${ }^{2}$ These changes can have a negative impact on employment, daily routines and relationships with other family members. ${ }^{3}$ Some parents of cancer patients may be able to cope adequately with the diagnosis, but a significant number suffer from mental weariness, nervousness, post-traumatic stress and feelings of hopelessness. ${ }^{4,5}$ Factors which can lead to depression or other psychological conditions among the parents of children diagnosed with cancer include the deterioration of the child's health, any behavioural or conduct problems on the part of the child, frequent visits to hospitals and a previous diagnosis of cancer in the family. ${ }^{5,6}$ Looking after a child with cancer can also result in health problems that do not usually occur among parents with healthy children. ${ }^{7}$ One study investigating the parents of children or adolescents in chronic pain noted that the parents were required to pay exceptionally close attention to their sick child's healthcare needs, a factor which notably increased their stress levels. ${ }^{8}$ Depression among parents of children with cancer has been strongly associated with conduct problems/externalising disorders on the part of the sick child; in addition, the degree of family cohesiveness may also play a role in sustaining symptoms of depression. ${ }^{9}$

Common symptoms of depression include helplessness, hopelessness, feelings of guilt, reduced energy, restlessness, an inability to sleep or oversleeping and problems concentrating or making decisions. ${ }^{10,11}$ Levels of depression among the parents of children with cancer have been reported as high, even very soon after the diagnosis. ${ }^{12}$ Further research indicates that when symptoms of depression start at a moderate to high level, depression may affect the parent for a longer time. ${ }^{13}$ Unfortunately, depressed parents are often not able to adequately care for children who require intensive cancer treatment and health management. ${ }^{14}$ Kostak et al. reported that the parents of children with cancer who have predisposing factors to developing depression require support from expert consultants in order to make the required lifestyle adjustments to suitably manage the diagnosis. ${ }^{3}$

To the best of the authors' knowledge, there is limited information from Basrah, Iraq, with regards to depression levels among the parents of children diagnosed with cancer. Due to the scarcity of studies regarding this important health issue, this study was conducted to shed light on the prevalence and levels of depression among the parents of children with cancer in this region and the factors which affect these levels. This study sought to investigate potential associations between levels of depression and various parental and child sociodemographic factors.

\section{Methods}

This cross-sectional study was conducted between November 2014 and April 2015 at the inpatient and outpatient clinics of the Specialist Paediatric Hospital in Basrah, Iraq. Either the mother or father of 384 children diagnosed with cancer and admitted to the hospital for treatment or follow-up during the study period were invited to participate in the study. The inclusion criteria included parents with children younger than 16 years old who had been diagnosed with any type of cancer at least two months' previously but still within the last year. ${ }^{15}$ Parents with a past or current diagnosis of psychiatric illness or those who were undergoing treatment for depression were excluded from the study. Those who had suffered a death in the family within six months of the study were also excluded. Consecutive parents who fulfilled the inclusion criteria and agreed to participate were included in the study. The sample size was calculated assuming a prevalence rate of $50 \%$, with a precision degree of 0.05 at the $95 \%$ confidence interval. ${ }^{2,4,14,16}$

A two-part English-language questionnaire was designed for use during face-to-face interviews with the participants. It was translated into Arabic by one of the researchers. All of the interviews were conducted by a single researcher. The first part of the questionnaire focused on the sociodemographic characteristics of the parents, including age, gender, number of years of education, occupation, monthly income, number of children overall and place of residence. In addition, characteristics of the children diagnosed with cancer were also elicited, including age, gender, type of cancer and time since diagnosis. The second part of the questionnaire sought to measure the presence and level of depression among the parents using the Center for Epidemiological Studies Depression Scale (CES-D), which consists of 20 self-reported items. ${ }^{17} \mathrm{To}$ minimise recall bias, the items focused on symptoms that the parents had experienced within the previous week. Each CES-D item was scored from 0-3, with higher scores suggesting depressive symptoms. The potential total score was out of 60 , with a score of $<15$ indicating no depression, 15-21 mild to moderate depression and $>21$ major depression. 
Table 1: Characteristics of parents* of children with cancer in Basrah, Iraq $(\mathrm{N}=336)$

\begin{tabular}{|c|c|}
\hline Characteristic & n (\%) \\
\hline \multicolumn{2}{|l|}{ Gender of parent } \\
\hline Male & $112(33.3)$ \\
\hline Female & $224(66.7)$ \\
\hline \multicolumn{2}{|l|}{ Mean age in years \pm SD } \\
\hline Fathers & $37.1 \pm 5.9$ \\
\hline Mothers & $31.9 \pm 5.3$ \\
\hline \multicolumn{2}{|c|}{ Education of father in years } \\
\hline$<12$ & $110(32.7)$ \\
\hline$\geq 12$ & $226(67.3)$ \\
\hline \multicolumn{2}{|c|}{ Education of mother in years } \\
\hline$<12$ & $204 .(60.7)$ \\
\hline$\geq 12$ & $132(39.3)$ \\
\hline \multicolumn{2}{|l|}{ Occupation of father } \\
\hline Government employee & $220(65.5)$ \\
\hline Private sector employee & $86(25.6)$ \\
\hline Retired & $3(0.9)$ \\
\hline Unemployed & $27(8.0)$ \\
\hline \multicolumn{2}{|l|}{ Occupation of mother } \\
\hline Housewife & $304(90.5)$ \\
\hline Employed & $32(9.5)$ \\
\hline \multicolumn{2}{|l|}{ Monthly income in IQD } \\
\hline$<500,000$ & $136(40.5)$ \\
\hline $500,000-1,000,000$ & $70(20.8)$ \\
\hline$>1,000,000$ & $130(38.7)$ \\
\hline \multicolumn{2}{|l|}{ Residence } \\
\hline Urban & $137(40.8)$ \\
\hline Rural & $199(59.2)$ \\
\hline \multicolumn{2}{|l|}{ Number of children } \\
\hline $1-3$ & $108(32.1)$ \\
\hline$\geq 4$ & $228(67.9)$ \\
\hline
\end{tabular}

Data were analysed using the Statistical Package for the Social Sciences (SPSS), Version 20 (IBM Corp., Chicago, Illinois, USA). Frequencies and percentages were calculated for the categorical variables (demographic characteristics of the parents and children). Chi-squared or Fisher's exact tests were used for the assessment of differences between variables. Quantitative data were expressed in means
Table 2: Characteristics of children with cancer in Basrah, Iraq ( $\mathrm{N}=336)$

$\begin{array}{lc}\text { Characteristic } & \mathbf{n}(\%) \\ \text { Mean age in years } \pm \text { SD } & 7.7 \pm 2.6 \\ \text { Mean time since diagnosis in months } \pm \text { SD } & 8.7 \pm 3.5 \\ \text { Gender } & \\ \text { Female } & 232(69.0) \\ \text { Male } & 104(31.0) \\ \text { Type of cancer } & \\ \text { Acute lymphoblastic leukaemia } & 150(44.6) \\ \text { Lymphoma } & 109(32.4) \\ \text { Neuroblastoma } & 28(8.3) \\ \text { Other* } & 49(14.6) \\ \text { SD standard deviation. } & \\ \text { "Including sarcomas, Wilms' tumours and retinoblastomas. }\end{array}$

and standard deviations. A $P$ value of $<0.050$ was considered statistically significant. A logistic regression analysis was performed to examine independent predictors of depression with depression categorised as either none, mild to moderate or severe.

The ethical committees of the College of Medicine at the University of Basrah and the Iraqi General Directorate of Health approved this study. Verbal consent was taken from all participants before they were enrolled in the study.

\section{Results}

Of the 384 parents of children with cancer invited to take part in this study, 336 participated (response rate: $87.5 \%$ ). The mean age of the fathers was 37.1 \pm 5.9 years, while the mean age of the mothers was $31.9 \pm 5.3$ years. A total of $67.9 \%$ of the parents had four children or more, including the child with cancer [Table 1]. The mean age of the children with cancer was $7.7 \pm 2.6$ years, with a mean time since diagnosis of $8.7 \pm 3.5$ months. The majority of the children were female (69.0\%). The most common type of cancer was acute lymphoblastic leukaemia (44.6\%), followed by lymphomas (32.4\%) [Table 2].

The overall prevalence of depression among the parents was $70.5 \%$ (95\% confidence interval [CI]: 65.5-75.3). Of these, $16.4 \%$ had mild to moderate depression, while $54.1 \%$ had major depression. Mothers had a higher prevalence of depression than fathers ( $77.2 \%$ and $57.1 \%$, respectively). In total, $60.7 \%$ of the mothers had major depression, while only $16.5 \%$ had mild to moderate depression. In contrast, $16.0 \%$ of the fathers exhibited signs of mild to moderate depression 
Table 3: Associations between parental and child characteristics and levels of depression among parents* of children with cancer in Basrah, Iraq $(\mathrm{N}=336)$

$\begin{array}{cccc}\text { No } & \text { n (\%) } & \begin{array}{c}\boldsymbol{P} \\ \text { value }\end{array} \\ \text { depression } & \begin{array}{c}\text { Mild to } \\ \text { moderate } \\ \text { depression }\end{array} & \begin{array}{c}\text { Major } \\ \text { depression }\end{array} & \\ & & \end{array}$

Parental characteristic

Gender of parent

Male

$48(42.9)$

$18(16.0)$

Female

$51(22.8)$

$37(16.5)$

$36(60.7)$

Age of father in years

$<30$

$$
9(36.0)
$$

$6(24.0)$

$10(40.0)$

30-39

$57(30.0)$

$28(14.7)$

$105(55.3)$

$40-49$

$27(25.7)$

$18(17.1)$

$60(57.1)$

$\geq 50$

$6(37.5)$

$3(18.8)$

$7(43.8)$

Age of mother in years

$<30$

$30(30.9)$

18 (18.6)

$49(50.5)$

30-39

$62(28.6)$

$33(15.2)$

$122(56.2)$

$40-49$

7 (31.8)

4. (18.2)

$11(50.0)$

Education of father in years

$<12$

30 (27.3)

$18(16.4)$

$62(56.4)$

$\geq 12$

69 (30.5)

$37(16.4)$

$120(53.1)$

Education of mother in years

$<12$

$$
43 \text { (21.1) }
$$

36 (17.6)

$125(61.3)$

$\geq 12$

$56(42.4)$

$19(14.4)$

$57(43.2)$

Occupation of father

$\begin{array}{lccc}\begin{array}{l}\text { Government } \\ \text { employee }\end{array} & 74(33.6) & 36(16.4) & 110(50.0) \\ \begin{array}{l}\text { Private sector } \\ \text { employee }\end{array} & 19(22.1) & 14(16.3) & 53(61.6) \\ \begin{array}{l}\text { Retired } \\ \text { Unemployed }\end{array} & 6(22.2) & 4(14.8) & 17(63.0) \\ & 0(0.0) & 1(33.3) & 2(66.7)\end{array}$

\section{Occupation of mother}

$\begin{array}{lccc}\begin{array}{l}\text { Housewife } \\ \text { Government } \\ \text { employee }\end{array} & 11(34.4) & 9(28.1) & 12(37.5) \\ \begin{array}{l}\text { Monthly income in IQD } \\ <500,000\end{array} & 17(12.5) & 19(14.0) & 100(73.5) \\ \begin{array}{l}500,000 \\ -1,000,000\end{array} & 12(17.10) & 19(27.1) & 39(55.7) \\ >1,000,000 & 70(53.8) & 17(13.1) & 43(33.1) \\ \text { Residence } & & & \\ \text { Urban } & 46(33.6) & 27(19.7) & 64(46.7) \\ \text { Rural } & 53(26.6) & 28(14.1) & 118(59.3)\end{array}$

0.001

0.679

0.814

0.001

\section{Number of children}

0.111

$\begin{array}{llll}1-3 & 32(29.6) & 24(22.2) & 52(48.1) \\ \geq 4 & 67(29.4) & 31(13.6) & 130(57.0)\end{array}$

Child characteristic

Age in years

0.584

$<5 \quad 22(33.3) \quad 14(21.2) \quad 30(45.5)$

$5-10$

$64(28.2) \quad 35(15.4) \quad 128(56.4)$

$11-15$

$13(30.2)$

$6(14.0)$

$24(55.8)$

Gender

Male

$35(33.7)$

$12(11.5)$

$57(54.8)$

Female

64 (27.6)

$43(18.5)$

$125(53.9)$

Type of cancer

0.062

$\begin{array}{lccc}\text { ALL } & 45(30.0) & 21(14.0) & 84(56.0) \\ \text { Lymphoma } & 28(25.7) & 16(14.7) & 65(59.6) \\ \text { Neuroblastoma } & 5(17.9) & 8(28.6) & 15(53.6) \\ \text { Other }^{\dagger} & 21(42.9) & 10(20.4) & 18(36.7)\end{array}$

$I Q D=$ Iraqi dinar $; A L L=$ acute lymphoblastic leukaemia .

*Either the mother or father of each child with cancer but not both.

'Including sarcomas, Wilms' tumours and retinoblastomas.

and $41.1 \%$ showed signs of major depression. This gender difference was significant $(P=0.001)$. No signi-ficant associations were found between levels of parental depression and the age, place of residence or occupation of the parents or the age, gender or type of cancer of the children. Years of education were inversely and significantly associated with depression for the mothers $(P=0.001)$; however, no significant association with this variable was observed among the fathers $(P=0.814)$. Major depression was more frequent among parents with a lower monthly income compared to those with higher incomes $(73.5 \%$ versus $33.1 \%)$, which was a highly significant difference $(P=0.001)$ [Table 3]. After logistic regression analysis, the association of depression with parental gender (odds ratio [OR]: 1.96; 95\% CI: 1.14-3.37; $P=0.017$ ) and monthly income (OR: 5.6; 95\% CI: 2.7-11.6; $P=0001)$ remained significant.

\section{Discussion}

This study found a high prevalence of depression among the parents of children with cancer in Basrah, Iraq; these findings are consistent with those of previous studies. ${ }^{2,3,18,19}$ Significant gender differences in the levels of depression among parents of children with cancer were also noted in the current study, especially with regards to major depression. In particular, mothers of children with cancer at any stage 
of treatment or off treatment demonstrated a higher level of depressive symptoms than the fathers; this result is in agreement with other studies. ${ }^{2,3,11,20-22}$ This gender difference could be due to variations in stress reactions to childhood cancer or because women may be more likely to report their problems compared with men. ${ }^{12,23}$ Mothers of children with cancer also often spend greater amounts of time caring for a sick child compared to fathers; due to cultural and economic obligations, fathers often spend more time at work, enabling them greater access to sources of external support, and they may hence feel less depressed. ${ }^{3}$ In the current study, the majority of parents had four children or more; this factor may also contribute to increased stress among the mothers, who may need to balance care of their other children in addition to their responsibilities caring for the sick child. However, no significant association was noted between the number of children in the family and levels of depression.

In the current study, rates of depression decreased significantly in relation to the number of years the mothers had been educated. Thus, women with higher educational attainment reported fewer depressive symptoms, a finding which is in agreement with other research. ${ }^{4,24-26}$ In contrast, several studies have shown no significant association between depression levels and education. ${ }^{3,27}$ In Iraq, women with more advanced educational qualifications may have reduced depression levels due to the protective effect of education against depression and anxiety, for which a gender difference has been noted. ${ }^{28,29}$ Education itself can also bestow an enhanced sense of control over an individual's surroundings. ${ }^{2}$

In the present study, a significant difference was also noted between depression levels and monthly income. Other studies are in agreement with this finding;, ${ }^{3,4}$ however, Erkan et al. did not find a statistically significant association between family income and parents' levels of depression. ${ }^{27}$ Iqbal et al. also showed no significant relationship between parents' depression levels and their socioeconomic status. $^{2}$ However, Kupst et al. reported that coping mechanisms are affected by income and educational levels. ${ }^{30}$ Low income, along with the financial burden of expensive medical treatments, cause added strain on families in addition to the trauma resulting from the devastating diagnosis of cancer in a child. Depression levels among poorer families may therefore increase following a diagnosis of cancer in a child, as depression is already more prevalent among families of lower socioeconomic status. ${ }^{31,32}$ In contrast, no significant association was found between depression levels and the parents' occupations in the current study. Simi- larly, no significant associations were found between levels of depression among parents and the ages of the parents and the age, gender or type of cancer of the child, which is in agreement with previous studies. ${ }^{2-4,27}$

Based on the findings of this study, specialist healthcare providers in Basrah should assess parents at risk of developing depression after their child has been diagnosed with cancer and consider enrolling them in intervention programmes. Parents should also receive support from social workers and perhaps financial aid from social security in order to help prevent further psychological deterioration, which would affect their ability to care for their sick child. However, an additional community-based study is indicated to determine base levels of depression among parents of healthy children in Basrah as, due to the cross-sectional nature of this study, the lack of a control group precludes inferences of causality among the variables. Nevertheless, despite this limitation, the results of the current study are comparable to published findings.

\section{Conclusion}

This study showed a high prevalence of depression, particularly major depression, among the parents of children diagnosed with cancer in Basrah. Depression was significantly more common and more severe among mothers and among parents with a lower income; as such, gender and income were significant independent predictors of depression. Based on these findings, parents at risk of developing depression after their child has been diagnosed with cancer should be enrolled in intervention programmes. Moreover, they should receive additional social and financial support. Levels of depression among the parents of healthy children in Basrah should be assessed in future community-based studies.

\section{CONFLICT OF INTEREST}

The authors declare no conflicts of interest.

\section{FUNDING}

No funding was received for this study.

\section{References}

1. Klassen AF, Gulati S, Granek L, Rosenberg-Yunger ZR, Watt L, Sung L, et al. Understanding the health impact of care giving: A qualitative study of immigrant parents and single parents of children with cancer. Qual Life Res 2012; 21:1595-605. doi: 10.1007/s11136-011-0072-8.

2. Iqbal A, Siddiqui KS. Depression among parents of children with acute lymphoblastic leukemia. J Ayub Med Coll Abbottabad 2002; 14:6-9. 
3. Kostak MA, Avci G. Hopelessness and depression levels of parents of children with cancer. Asian Pac J Cancer Prev 2013; 14:6833-8. doi: 10.7314/APJCP.2013.14.11.6833.

4. Kholasehzadeh G, Shiryazdi S, Neamatzadeh H, Ahmadi N. Depression levels among mothers of children with leukemia. Iran J Ped Hematol Oncol 2014; 4:109-13.

5. Maurice-Stam H, Oort FJ, Last BF, Grootenhuis MA. Emotional functioning of parents of children with cancer: The first five years of continuous remission after the end of treatment. Psychooncology 2008; 17:448-59. doi: 10.1002/pon.1260.

6. Boman KK, Kjällander Y, Eksborg S, Becker J. Impact of prior traumatic life events on parental early stage reactions following a child's cancer. PLoS One 2013; 8:e57556. doi: 10.1371/journal. pone.0057556.

7. Hoekstra-Weebers JE, Jaspers JP, Kamps WA. Klip EC. Risk factors for psychological maladjustment of parents of children with cancer. I Am Acad Child Adolesc Psychiatry 1999; 38:1526-35. doi: 10.1097/00004583-199912000-00014.

8. Palermo TM, Eccleston C. Parents of children and adolescents with chronic pain. Pain 2009; 146:15-7. doi: 10.1016/j.pain. 2009.05.009.

9. ManneSL, Lesanics D, Meyers P, Wollner N, Steinherz P, Redd W. Predictors of depressive symptomatology among parents of newly diagnosed children with cancer. J Pediatr Psychol 1995; 20:491-510. doi: 10.1093/jpepsy/20.4.491.

10. Norberg AL, Lindblad F, Boman KK. Parental traumatic stress during and after paediatric cancer treatment. Acta Oncol 2005; 44:382-8. doi: 10.1080/02841860510029789.

11. Barrera M, D'Agostino NM, Gibson J, Gilbert T, Weksberg R, Malkin D. Predictors and mediators of psychological adjustment in mothers of children newly diagnosed with cancer. Psychooncology 2004; 13:630-41. doi: 10.1002/pon.765.

12. Yeh $\mathrm{CH}$. Gender differences of parental distress in children with cancer. J Adv Nurs 2002; 38:598-606. doi: 10.1046/j.13652648.2000.02227.x

13. Vrijmoet-Wiersma CM, van Klink JM, Kolk AM, Koopman HM, Ball LM, Maarten Egeler R. Assessment of parental psychological stress in paediatric cancer: A review. J Pediatr Psychol 2008; 33:694-706. doi: 10.1093/jpepsy/jsn007.

14. Ghufran M, Andrades M, Nanji K. Frequency and severity of depression among mothers of children with cancer: Results from a teaching hospital in Karachi, Pakistan. Br J Med Pract 2014; 7:a701.

15. Kendler KS, Myers J, Zisook S. Does bereavement-related major depression differ from major depression associated with other stressful life events? Am J Psychiatry 2008; 165:1449-55. doi: 10.1176/appi.ajp.2008.07111757.

16. Naing L, Winn T, Rusli BN. Practical issues in calculating the sample size for prevalence studies. Arch Orofac Sci 2006; 1:9-14.

17. Radloff LS. The CES-D scale: A self-report depression scale for research in the general population. Appl Psychol Meas 1977; 1:385-401. doi: 10.1177/014662167700100306

18. Sharan P, Mehta M, Chaudhry VP. Psychiatric disorders among parents of children suffering from acute lymphoblastic leukemia. Pediatr Hematol Oncol 1999; 16:43-7. doi: 10.1080/ 088800199277588
19. Magni G, Silvestro A, Carli M, De Leo D. Social support and psychological distress of parents of children with acute lymphocytic leukaemia. Br J Med Psychol 1986; 59:383-5. doi: 10.1111/j.2044-8341.1986.tb02708.x.

20. Allen R, Newman SP, Souhami RL. Anxiety and depression in adolescent cancer: Findings in patients and parents at the time of diagnosis. Eur J Cancer 1997; 33:1250-5. doi: 10.1016/S09598049(97)00176-7.

21. Dockerty JD, Williams SM, McGee R, Skegg DC. Impact of childhood cancer on the mental health of parents. Med Pediatr Oncol 2000; 35:475-83. doi: 10.1002/1096-911X (20001101)35:5<475::AID-MPO6>3.0.CO;2-U.

22. Norberg AL, Lindblad F, Boman K. Coping strategies in parents of children with cancer. Soc Sci Med 2005; 60:965-75. doi: 10.1016/j.socscimed.2004.06.030.

23. Sloper P. Predictors of distress in parents of children with cancer: A prospective study. J Pediatr Psychol 2000; 25:79-91. doi: 10.1093/jpepsy/25.2.79

24. Al-Homaidan HT. Depression among women with primary infertility attending an infertility clinic in Riyadh, Kingdom of Saudi Arabia: Rate, severity, and contributing factors. Int J Health Sci (Qassim) 2011; 5:108-15.

25. RamezanzadehF,AghssaMM,AbediniaN,ZayeriF,KhanafsharN, Shariat $M$, et al. A survey of relationship between anxiety, depression and duration of infertility. BMC Womens Health 2004; 4:9. doi: 10.1186/1472-6874-4-9.

26. Noorbala AA, Ramezanzadeh F, Abedinia N, Yazdi SA, Jafarabadi M. Study of psychiatric disorders among fertile and infertile women and some predisposing factors. J Fam Reprod Health 2007; 1:6-11.

27. Erkan S, Kaplan Y. A study on the depression levels of mothers of leukemic children. Pak J Soc Sci 2009; 6:42-7.

28. Ross CE, Mirowsky J. Sex differences in the effect of education on depression: Resource multiplication or resource substitution? Soc Sci Med 2006; 63:1400-13. doi: 10.1016/j. socscimed.2006.03.013

29. Bjelland I, Krokstad S, Mykletun A, Dahl AA, Tell GS, Tambs K. Does a higher educational level protect against anxiety and depression? The HUNT study. Soc Sci Med 2008; 66:1334-45. doi: 10.1016/j.socscimed.2007.12.019.

30. Kupst MJ. Family coping: Supportive and obstructive factors. Cancer 1993; 71:3337-41. doi: 10.1002/1097-0142 (19930515)71:10+<3337::AID-CNCR2820711733>3.0.CO;2-7.

31. Kessler RC, Berglund P, Demler O, Jin R, Koretz D, Merikangas KR, et al. The epidemiology of major depressive disorder: Results from the National Comorbidity Survey Replication (NCS-R). JAMA 2003; 289:3095-105. doi: 10.1001/ jama.289.23.3095.

32. Elcigil A, Conk Z. Determining the burden of mothers with children who have cancer. Deuhyo Ed 2010; 3:175-81. 